\title{
SiC-based MIS gas sensor for CO detection in very high water vapor environments
}

\author{
O. Casals ${ }^{1}$, Th. Becker ${ }^{2}$, P. Godignon ${ }^{3}$, A. Romano-Rodriguez ${ }^{1}$ \\ ${ }^{1}$ Universitat de Barcelona (UB), MIND-IN ${ }^{2} \cup B-D e p a r t m e n t$ of Electronics, c/Martí i Franquès 1, 8028 \\ Barcelona, Spain.ocasals@el.ub.es \\ ${ }^{2}$ EADS Innovation Works, Nesspriel 1, 21129 Hamburg, Germany. \\ ${ }^{3}$ Institut de Microelectrònica de Barcelona, IMB-CNM-CSIC, Campus UAB, E-08193 Bellaterra, Spain.
}

\begin{abstract}
:
Due to their feasibility to operate at high temperature in environments with extremely high concentrations of water vapor (up to $45 \%$ by volume ratio to nitrogen), SiC-based MIS (MetalInsulator-Semiconductor) capacitors are good candidates to monitor the presence of $\mathrm{CO}$ in the exhaust gases of hydrogen- or hydrocarbon-based fuel cells. In this work, we show that these devices are able to detect down to $2 \mathrm{ppm}$ of $\mathrm{CO}$ and that their response is hardly affected by the presence of high concentrations of $\mathrm{CO}_{2}$ or by extremely high water vapor concentrations in pure nitrogen.
\end{abstract}

Key words: MIS (Metal-Insulator-Semiconductor), sensor, $\mathrm{CO}$, water vapor, $\mathrm{CO}_{2}$, hydrogen- or hydrocarbons-based fuel cells.

\section{Introduction}

Amongst the different types of solid-state gas sensors, field-effect based sensors have shown to be suitable devices to detect hydrogen and hydrocarbons if a catalytic metal layer is used as a gate. Since Lundström et al. [1] reported on hydrogen-sensitive Pd-MOS (Metal-OxideSemiconductor) transistors fabricated on conventional silicon substrates, in 1975, fieldeffect based sensors has experienced significant advances. On the one hand, the use of wide band gap semiconductor such as $\mathrm{SiC}$, group-III nitrides (AIN, GaN and AIGaN) and diamond, allows this kind of sensors to work at higher temperatures than Si-based devices. The higher operation temperature results in a larger responses to hydrogen and hydrocarbons as well as in better response and recovery times [2]. Additionally, these devices withstand the exposure to hazardous gases, which are usually produced in high temperature conditions. On the other hand, the use of a porous and/or discontinue catalytic gate has widened the range of gases to which these devices respond to non-hydrogen-containing species such $\mathrm{CO}[3,4]$.

According to the most accepted model for MIS (Metal-Insulator-Semiconductor) sensors, the sensing mechanism to hydrogen or hydrocarbons can be attributed to the formation of $\mathrm{H}$-induced dipole layer at the metal-insulator interface [1]. However, the studies on the sensitivity of MIS devices towards nonhydrogen-containing species such $\mathrm{CO}$ have been relatively scarce and the sensing mechanism requires further investigation $[5,6]$.

Recently, we have demonstrated that $\mathrm{Pt} / \mathrm{TaO}_{x} / \mathrm{SiO}_{2} / \mathrm{SiC} \mathrm{MIS}$ capacitors can operate not only at high temperature, but also, in the presence of extremely high water vapor concentrations gases (up to $45 \%$ by volume) [7]. In these harsh conditions, these devices are still able to detect hydrogen and hydrocarbons in concentrations far below the legal permissible exposure limits $[8,9]$ or the requirements for hydrogen safety sensors [10]. This fact makes $\mathrm{Pt} / \mathrm{TaO}_{\mathrm{x}} / \mathrm{SiO}_{2} / \mathrm{SiC}$ MIS capacitors suitable to monitor the proper operation of devices such as hydrogen or hydrocarbon-based fuel cells, whose exhaust gases contain extremely high concentrations of water vapor and $\mathrm{CO}_{2}$ but can also contain remains of the fuel, oxygen and byproducts of the catalytic reaction, such as $\mathrm{CO}$, if the combustion is incomplete.

In this work, the performance of $\mathrm{Pt} / \mathrm{TaO}_{\mathrm{x}} / \mathrm{SiO}_{2} / \mathrm{SiC}$ MIS capacitors operating as $\mathrm{CO}$ sensors in atmospheres with extremely high water vapor concentrations and in presence of $\mathrm{CO}_{2}$ is investigated. The suitability of these sensors to monitor $\mathrm{CO}$ in the exhaust of devices such as hydrogen- or hydrocarbonbased fuel cells is discussed. Under the light of the here-reported experimental results a critical 
review of the CO sensing mechanisms in MIS devices is also presented.

\section{Experimental}

$\mathrm{Pt} / \mathrm{TaO}_{x} / \mathrm{SiO}_{2} / \mathrm{SiC}$ MIS capacitors have been fabricated on n-type (0001) Si-face 4H-SiC substrates with a $10-\mu \mathrm{m}$ epitaxial layer (doping level $10^{16} \mathrm{~cm}^{-3}$ ) grown on heavily doped substrate $(0.021 \Omega)$ purchased from CREE Inc. A detailed description of the fabrication process can be found elsewhere [7,11]. After their fabrication, the devices were annealed in alternating reducing and oxidizing atmospheres at temperatures above $600^{\circ} \mathrm{C}$ for at least 2 hours in order to obtain a porous gate layer with stable electrical properties [3]. The final layered structure of the MIS capacitors is sketched in Fig. 1.

The MIS capacitor response to gases was measured as the gate voltage change $\left(\Delta \mathrm{V}=\mathrm{V}_{\mathrm{G}}(\right.$ gas $\left.)-\mathrm{V}_{\mathrm{G}}\left(\mathrm{N}_{2}\right)\right)$ under constant capacitance conditions. Water vapor concentrations ranging from $3 \%$ (equivalent to $80 \%$ relative humidity at room temperature $25^{\circ} \mathrm{C}$ - and $1 \mathrm{~atm}$ ) to $45 \%$ by volume ratio to gas were obtained by mixing ultrapure water with the gas flux in a Bronkhorst controlled evaporator and mixer (CEM) at ${ }^{\circ} \mathbf{2 0 0}$ and atmospheric pressure. Water vapor condensation was avoided by thermalizing the gas test chamber and all the pipes at $200^{\circ} \mathrm{C}$.

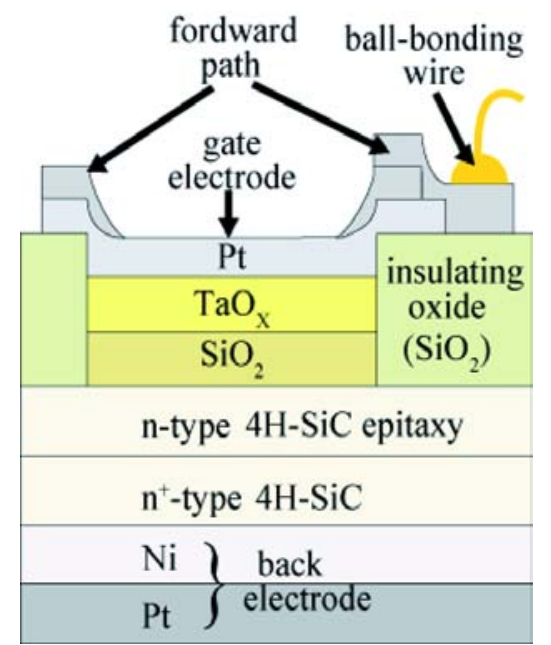

Fig. 1 Schematic diagram of the layers that comprise the MIS capacitors. Reprinted from [7], with permission from Elsevier.

\section{Results and discussion}

In nitrogen atmosphere, the presence of water vapor (up to $45 \%$ concentrations) at temperatures ranging from 200 to $400^{\circ} \mathrm{C}$ did not produce any significant change in the admittance curves (Fig. 2). No degradation of the electrical performance of the devices was observed after days of working under these water vapor rich conditions. This remarkable insensitivity and stability can be explained by 1 ) the fact that the water vapor dissociation on $\mathrm{Pt}$ surfaces, which could lead to $\mathrm{H}$ atoms that could reach the metal-insulator interface, is unlikely at the temperatures used in this work [12]; and 2) the interaction between water vapor molecules and the surface of the $\mathrm{TaO}_{x}$ layer exposed through the Pt porous gate does not produce any electrically measurable effect.

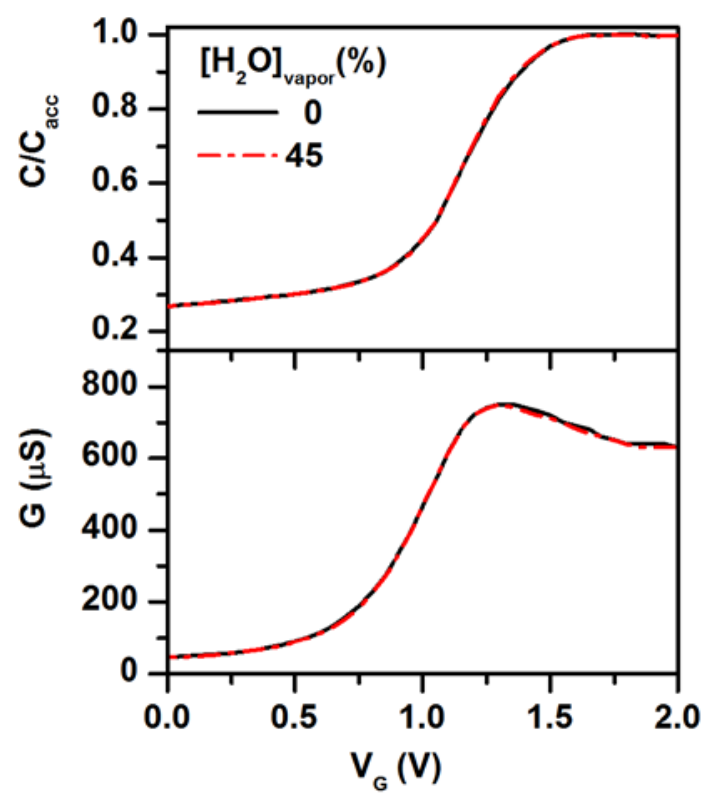

Fig. 2 Admittance versus gate voltage curves ( $C-V_{G}$ and $\mathrm{G}-\mathrm{V}_{\mathrm{G}}$ ) of a $\mathrm{Pt} / \mathrm{TaO} \mathrm{O}_{\star} / \mathrm{SiO}_{2} / \mathrm{SiC}$ MIS capacitor operating at 250 in dry nitrogen and in the presence of $45 \%$ of water vapor. Reprinted from [7], with permission from Elsevier.

The dynamic response of a $\mathrm{Pt} / \mathrm{TaO}_{x} / \mathrm{SiO}_{2} / \mathrm{SiC}$ MIS capacitor to pulses of $\mathrm{CO}$ from 1 to $20 \mathrm{ppm}$ in different water vapor concentrations is shown in Fig. 3. The detection limit to $\mathrm{CO}$ of these MIS capacitors at any water vapor content is around $2 \mathrm{ppm}$, since the response to $1 \mathrm{ppm}$ is just in the limit of experimental error $(10 \mathrm{mV})$. This performance is suitable to monitor the more restrictive permissible exposure limits $(8.6 \mathrm{ppm}$ for 8 hours TWA according to WHO [13]). It is noteworthy that the water vapor changes in the gas mixture hardly have any effect neither on the sensor's response nor on the response and recovery times. This result hints that $\mathrm{CO}$ and water vapor molecules neither compete for the same adsorption sites nor interact between them at the sensor's surface.

The influence of $\mathrm{CO}_{2}$ on the sensor's ability to detect $\mathrm{CO}$ has also been studied. Fig. 4 shows that the introduction of $1 \% \mathrm{CO}_{2}$ in the test chamber hardly interferes in the MIS capacitors' response to $\mathrm{CO}$. Likewise, the device did not show any significant response to $\mathrm{CO}_{2}$ in the range of temperatures studied neither. 
All these results demonstrate that the herepresented MIS sensors are suitable to target $\mathrm{CO}$ detection in water vapor and $\mathrm{CO}_{2}$ rich atmospheres.

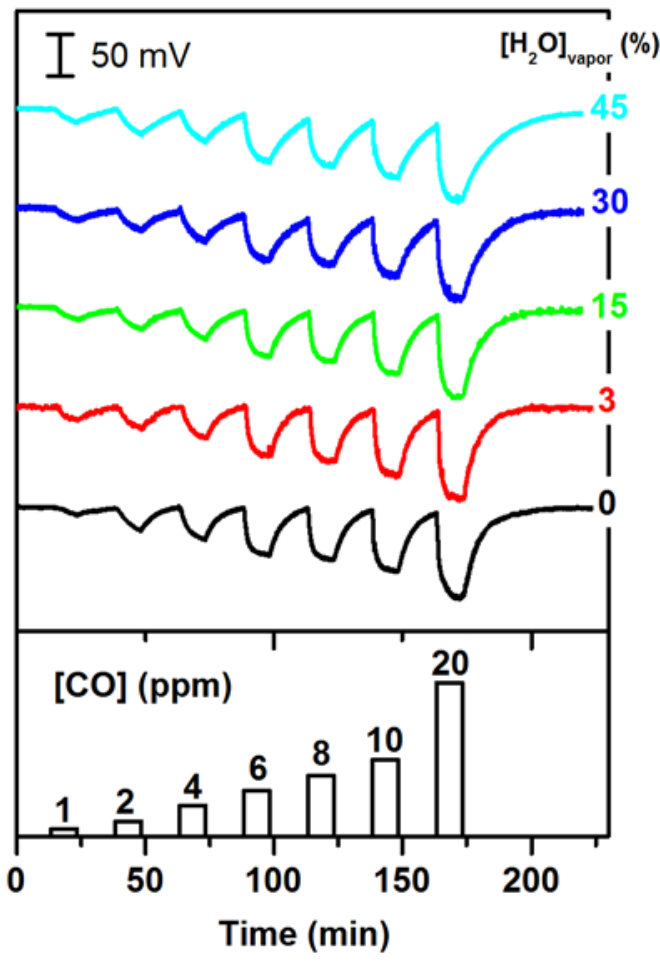

Fig. 3 Dynamic response of a $\mathrm{Pt} / \mathrm{TaO}{ }_{\times} / \mathrm{SiO}_{2} / \mathrm{SiC}$ MIS capacitor a) to pulses of $\mathrm{CO}$ in different vapor containing atmospheres at $300^{\circ} \mathrm{C}$.

The response versus the $\mathrm{CO}$ concentration curve was found to follow eq. (1),

$$
\Delta V([C O])=\Delta V_{\max } \cdot \frac{k \cdot[C O]}{1+k \cdot[C O]}
$$

where $\Delta V_{\max }$ and $k$ are constants dependent on the temperature. This equation is based on the Langmuir's isotherm for non-dissociative adsorption and implies the assumption that the sensor's response is proportional to the amount of $\mathrm{CO}$ molecules adsorbed at the sensor's surface. Hence, $\Delta \mathrm{V}_{\max }$ is the voltage change measured when all the available $\mathrm{CO}$ adsorption sites of the sensor's surface are occupied. The agreement with our experimental data demonstrates that $\mathrm{CO}$ molecules are nondissociatively adsorbed on $\mathrm{Pt}$. This fact is also supported by surface science [12] and in situ drift studies of the Pt-gate surfaces of similar devices [5,6]. However, MIS devices with a dense hardly respond to $\mathrm{CO}$ and, therefore, the molecular adsorption on the $\mathrm{Pt}$ surface alone cannot explain the sensitivity of MIS devices to this gas. Moreover, $\mathrm{CO}$ adsorbates lead to a positive change in the work function, like in the case of $\mathrm{O}_{2}$, whereas the sign of the MIS sensors' response to these gases is just the opposite.

In order to explain this behavior, it has been suggested that the $\mathrm{CO}$ sensing mechanism for this kind of devices could be related to the modulation of the magnitude or the quantity of remaining hydrogen dipoles at the metal-oxide interface by the $\mathrm{CO}$ adsorption at the Pt surface [14]. Alternatively, it has also been proposed that the sensor signal is produced by the removal of oxygen from partially oxidized $\mathrm{Pt}$, which was directly observed on the surface of similar devices [3,5]. However, both theories fail to explain the lack of response to $\mathrm{CO}$ molecules in dense-gate devices or the reversibility of the $\mathrm{CO}$ effects on the devices in pure nitrogen atmospheres.

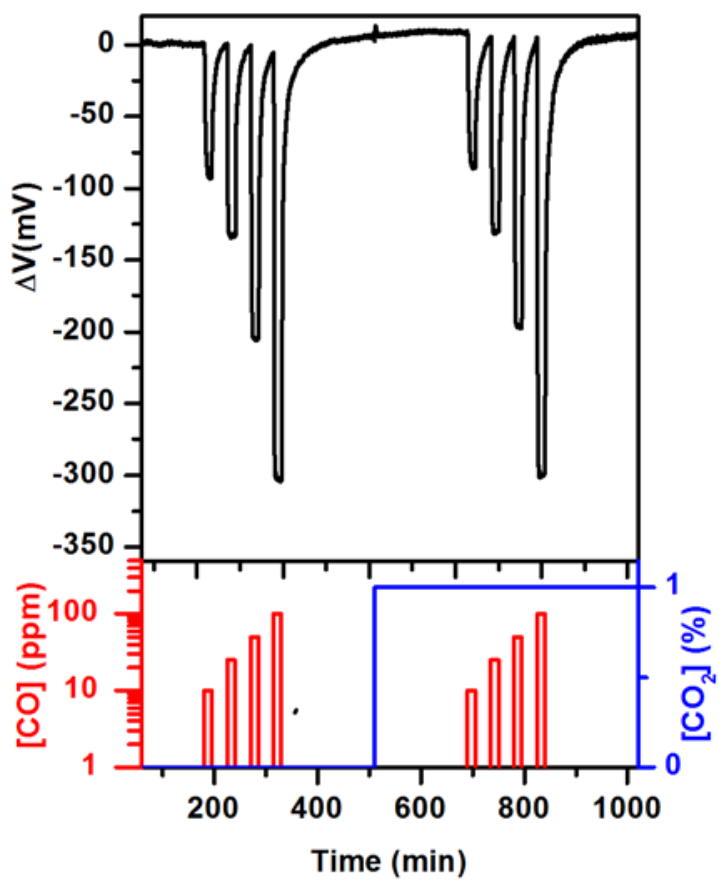

Fig. 4 Dynamic response of a $\mathrm{Pt} / \mathrm{TaO} \mathrm{O}_{x} / \mathrm{SiO}_{2} / \mathrm{SiC}$ MIS capacitor to pulses of $\mathrm{CO}$ in presence and absence of $1 \%$ of $\mathrm{CO}_{2}$ at $260^{\circ} \mathrm{C}$.

The CO spillover phenomenon (interphase diffusion of adsorbed atoms or molecules), which is common metal-assisted catalysis on mixed oxides [15-17], could provide a more consistent explanation. According to this, the sensor's response to $\mathrm{CO}$ could be attributed to $\mathrm{CO}$ molecules that, after being adsorbed at the $\mathrm{Pt}$ near the bare patches of $\mathrm{TaO}_{\mathrm{x}}$, migrate to this oxide via spillover $[3,18]$. Thus, the response signal would be modulated by the molecular adsorption of $\mathrm{CO}$ on the Pt surface of the devices, which is consistent with the experimental results. Likewise, the recovery of the sensor baseline signal after the removal of $\mathrm{CO}$ from the gas mixtures can be explained by the reverse spillover phenomenon. At the same 
time, the direct adsorption of the $\mathrm{CO}$ molecules at the surface of the exposed $\mathrm{TaO}_{\mathrm{x}}$ areas of the porous $\mathrm{Pt}$ electrode is also possible and it would also explain the lack of response in dense-gate devices. In any case, whatever is the way that drives the $\mathrm{CO}$ molecules to the $\mathrm{TaO}_{x}$ it leads to a modulation of the surface dipole layer in the exposed patches of this oxide by the formation of dipoles.

\section{Conclusions}

MIS capacitors are suitable to detect $\mathrm{CO}$ in challenging conditions, such is the ones found in the exhaust gases of hydrogen or hydrocarbons based fuel cells. The no crosssensitivity between water vapor (even at $45 \%$ by volume) and $\mathrm{CO}$ indicates that water vapor molecules do not compete with $\mathrm{CO}$ molecules for the adsorption sites. Likewise, the sensors are non-responsive to $\mathrm{CO}_{2}$ and its presence in the gas mixture hardly interferes in the capacitors' response to $\mathrm{CO}$. In these harsh measuring conditions, the devices are able to detect $\mathrm{CO}$ concentrations down to $2 \mathrm{ppm}$.

Under light of the here-presented results, the commonly proposed mechanism of the $\mathrm{CO}$ detection in this kind of devices seems to be the rather simplistic. Other mechanisms, such as spillover phenomenon are necessary to successfully explain all the experimental evidences.

\section{Acknowledgements}

This work has been partially supported by the Spanish Ministries of Science and Technology, through the project TIC2000-1403 and of Science and Innovation through the project TEC2007-67962-C04-04. O.C. is indebted to the Spanish Ministry of Education, Science and Sports for her FPU scholarship.

\section{References}

[1] K. I. Lundström, M. S. Shivaraman and C. M. Svensson, A Hydrogen-sensitive Pd-gate MOS transistor, Journal of Applied Physics 46, 38763881 (1975);

[2] A. L. Spetz, A. Baranzahi, P. Tobias, et al., High Temperature Sensors Based on Metal Insulator Silicon Carbide Devices, phys. stat. sol. (a) 162, 493 (1997)

[3] A. Spetz, F. Winquist, C. Nylander, et al., Modified palladium-gate MOS devices for ammonia gas detection, Proceedings of the (First) International Meeting on Chemical Sensors, 479-487 (1983)

[4] J. Schalwig, P. Kreisl, S. Ahlers, et al., Response mechanism of SiC-based MOS field-effect gas sensors, Sensors Journal, IEEE 2, 394-402 (2002);

[5] A. E. Åbom, P. Persson, L. Hultman, et al., Influence of gate metal film growth parameters on the properties of gas sensitive field-effect devices, Thin Solid Films 409, 233-242 (2002); 10.1016/s0040-6090(02)00135-9

[6] S. Nakagomi, G. Wingqvist, A. E. Åbom, et al., Hydrogen sensing by NKN thin film with high dielectric constant and ferroelectric property, Sensors and Actuators, B: Chemical 108, 490495 (2005); 10.1016/j.snb.2004.11.024

[7] O. Casals, T. Becker, P. Godignon, et al., SiCbased MIS gas sensor for high water vapor environments, accepted at Sensors and Actuators B: Chemical;

[8] ACGIH, Threshold limit values for chemical substances and physicalagents and biological exposure indices for 1994-1995, American Conference of Governmental Industrial Hygienists, Cincinnati. OH, (1994);

[9] C. Vahlberg, G. R. Yazdi, R. M. Petoral Jr, et al., Surface engineering of functional materials for biosensors, Proceedings of IEEE Sensors 2005, 504-507 (2005);

[10] W. J. Buttner, M. B. Post, R. Burgess, et al., An overview of hydrogen safety sensors and requirements, International Journal of Hydrogen Energy 36, 2462-2470 (2011); 10.1016/j.ijhydene.2010.04.176

[11] O. Casals, B. Barcones, A. Romano-Rodríguez, et al., Characterisation and stabilisation of $\mathrm{Pt} / \mathrm{TaSi} / \mathrm{SiO}_{2} / \mathrm{SiC}$ gas sensor, Sensors and Actuators B: Chemical 109, 119-127 (2005) 10.1016/j.snb.2005.03.008

[12] A. Bielanski and J. Haber, Oxygen in catalysis, New York (1991);

[13] Monitoring ambient air quality for health impact assessment, European series 85, WHO regional publications, Copenhagen, (1999); 928901351 6: 9289013516

[14] M. Eriksson and L.-G. Ekedahl, The influence of $\mathrm{CO}$ on the response of hydrogen sensitve PdMOS devices, Sensors and Actuators $B$ 42, 217223 (1997);

[15] V. Lesnyak, V. Yatsimirskii, O. Boldyreva, et al., Properties of the surface layer and catalytic activity of $\mathrm{Ta}_{2} \mathrm{O}_{5}$ with $\mathrm{Pt}$ or $\mathrm{Pd}$ additives in the oxidation of hydrogen, Theoretical and Experimental Chemistry 44, 189-194 (2008); 10.1007/s11237-008-9028-7

[16] V. I. Savchenko, $\mathrm{CO}_{\text {ads }}$ spillover and lowtemperature activity of heterophase catalysts in CO oxidation, Reaction Kinetics and Catalysis Letters 55, 143-151 (1995); 10.1007/bf02075845

[17] W. C. Conner and J. L. Falconer, Spillover in Heterogeneous Catalysis, Chemical Reviews 95, 759-788 (1995); 10.1021/cr00035a014

[18] M. Eriksson and L. G. Petersson, Spillover of hydrogen, oxygen and carbon monoxide in oxidation reactions on $\mathrm{SiO}_{2}$ supported $\mathrm{Pd}$, Surface Science 311, 139-152 (1994); 